\title{
Laser-induced degradation of organophosphorus compounds
}

\author{
Polonca Trebše and Mladen Franko \\ Nova Gorica Polytechnic, Laboratory for Environmental Research, P.O.B. 301, 5001 Nova Gorica, Slovenia
}

\begin{abstract}
The object of our research has been laser-induced photo-oxidation of organophosphorus compounds in aqueous media. A XeCl excimer laser with a pulse energy of up to $150 \mathrm{~mJ}$ and wavelength of $308 \mathrm{~nm}$ has been used as a light source. The research comprised the influence of irradiation conditions on pesticide degradation (number of laser pulses, pulse energy) and decomposition efficiency. The time between irradiation and sample isolation ranged from $5 \mathrm{~min}$ to $24 \mathrm{hrs}$. Rapid decomposition has been achieved within two hours following the irradiation for the range of concentrations limited by the solubility of pesticide (up to $40 \mathrm{mgL}^{-1}$ ). $1 \mathrm{~mL}$ samples required less than $120 \mathrm{~mJ}$ of total irradiation energy at $308 \mathrm{~nm}$, which was delivered to the sample in time intervals shorter then 1 second when catalysts, such as titanium dioxide and hydrogen peroxide were applied. Similar degradation efficiency was also obtained without the addition of catalysts when higher irradiation energies were used. The compounds detected in the irradiated samples suggest that diazinon is converted directly into 2-isopropyl-4-methyl-6-hydroxypyrimidine without the formation of more toxic diazoxon. This transformation involves oxidation of the sulphur atom to the sulphate anion.
\end{abstract}

\section{INTRODUCTION}

Organophosphorus compounds which are mostly used in agriculture as pesticides represent an attempt to maximise insecticide activity and minimise environmental persistence. They have replaced organochlorine compounds because these persist and accumulate in the environment. Different pathways of diazinon decomposition such as hydrolysis, photolitic oxidation, microbial transformations and other biological processes were intensively investigated recently [1]. (Scheme 1)

Hydrolysis is the most common degradation pathway, because organophosphorus esters are very susceptible to it. In some cases hydrolysis occurs at several reactive centres in a given organophosphorus pesticide molecule. The phosphate ester bond can be treated as a weak bond and its cleavage leads to detoxification of a pesticide. Its susceptibility to hydrolysis depends mostly on electron deficiency of the phosphorus atom. The second important factor affecting hydrolysis is the $\mathrm{pH}$. Diazinon, for example, is rapidly hydrolysed at low or high $\mathrm{pH}$ values since it is susceptible to base- and also acid-catalysed hydrolysis [2-4].

Since oxygen is more electron withdrawing than sulphur, oxo-derivatives are less stable with regard to hydrolysis than the thio substituted pesticides.

Exposure of different organophosphorus compounds to light results in photolytic degradation $[5,6]$. In the past, three main light sources had been used for photolysis experiments; natural summer sunlight, the suntest apparatus and $\mathrm{Hg}$ lamps. It was demonstrated, that the use of different light sources under identical conditions produces the same products. The only difference is the kinetics of reactions. Chemical oxidation of selected compounds can be obtained by using photo assisted Fenton reaction $\left(\mathrm{Fe}^{3+} / \mathrm{H}_{2} \mathrm{O}_{2} / \mathrm{UV}\right.$ light) [7]. This reaction involves hydrogen peroxide, Fe(III) salts as catalysts and UV light. Photo assisted Fenton reaction is similar to some other oxidation processes, such as those using $\mathrm{H}_{2} \mathrm{O}_{2} / \mathrm{UV}, \mathrm{O}_{3} / \mathrm{H}_{2} \mathrm{O}_{2}$, $\mathrm{O}_{3} / \mathrm{UV}$, or semiconductor photo catalysis $\left(\mathrm{TiO}_{2} / \mathrm{UV}\right)$ [8-10]. Chemical oxidation of diazinon through chlorination [11] and ozonization has been studied, too [12]. In aqueous phase the oxidation product, diazoxon, has been further hydrolysed to diethylphosphate and 2-isopropyl-4-methyl-6-hydroxypyrimidine. The final products of ozonization are acetic acid and formic acid.

Many scientists have utilised aqueous suspension of semiconductors in combination with UV irradiation for degradation of different organic compounds, such as chlorinated compounds, and nitrogen-containing compounds [13]. Among the applied semiconductors, titanium dioxide $\left(\mathrm{TiO}_{2}\right)$ proved to be the most efficient one. The reason for this is in its capability to form electronhole pairs under illumination with UV light.

Several studies concerning advantages of hydrogen peroxide addition to samples of organic pollutants, such as chlorophenols and triazines, irradiated by UV light in $\mathrm{TiO}_{2}$ suspension have been published. The combinations of $\mathrm{UV}-\mathrm{H}_{2} \mathrm{O}_{2}, \mathrm{UV}-\mathrm{TiO}_{2}$ and $\mathrm{UV}-\mathrm{H}_{2} \mathrm{O}_{2}-\mathrm{TiO}_{2}$ have been used for photo degradation of some organophosphorus compounds, including diazinon. Recently, the application of excimer lasers as a source of light for different chemical transformations, such as photopolymerization and crosslinking, was reported, particularly because they provide monochromatic radiation of high 


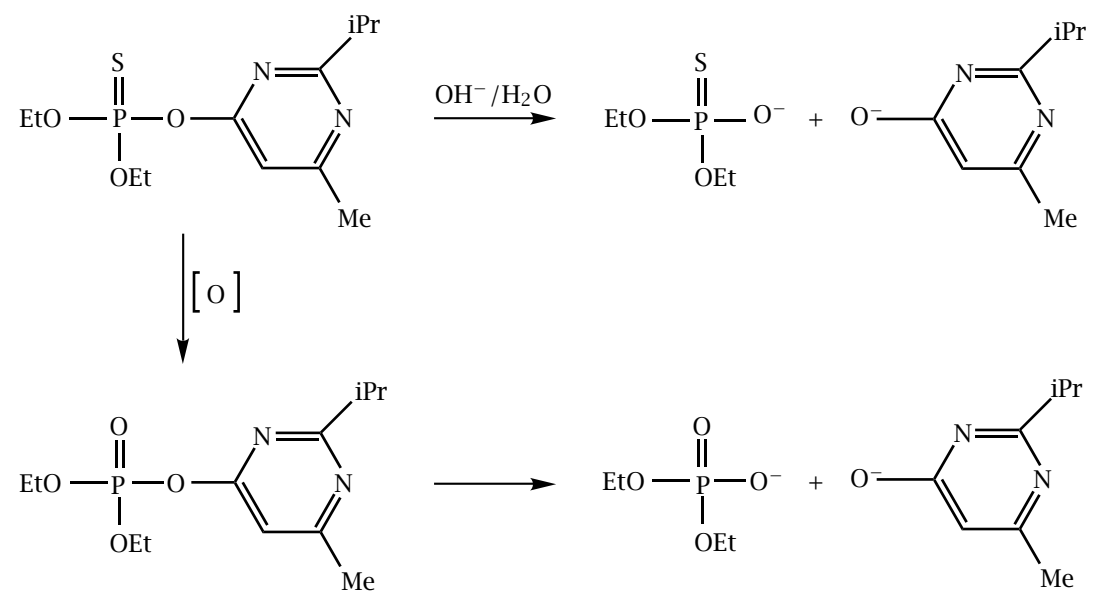

Scheme 1. Degradation pathways for diazinon.

intensity $[14,15]$. Apart from the nitrogen laser, providing an emission line at $227 \mathrm{~nm}$, the most frequently used lasers in chemistry are the excimer laser (in particular $\mathrm{XeCl}$, emitting light at $308 \mathrm{~nm}$ ) and the Nd:YAG laser (1060, 530, $355 \mathrm{~nm})$ [16].

On the basis of the examples described above, it is obvious that most reactions involve the use of different reagents which might be problematic from the ecological point of view unless additional techniques are used for their removal. In addition, all the experiments require longer irradiation times. Therefore we investigated the possibility to perform the photodegradation experiments using a stronger light source in combination with shorter irradiation times and without the addition of any potential pollutant to the sample mixture.

\section{MATERIALS AND METHODS}

2.1. Chemicals. We have chosen diazinon $(O, O$ diethyl-O-(diisopropyl-6-methyl-4-pyrimidyl) phosphorotioat), provided by Pestanal as a model substance. Other chemicals (the metabolite, 6-methyl-2- (1-methylethyl)-4(1H)-pyrimidone, and titanium(IV) oxide) have been purchased from Aldrich. Hydrogen peroxide has been provided by Fluka, acetonitrile (HPLC grade) and hexane (98\%) have been purchased from Merck.

Sample solutions have been prepared in deionized (nanopure) water.

2.2. The photodegradation procedure. Experiments have been carried out in a $1 \mathrm{~cm} \times 1 \mathrm{~cm}$ cuvette, using an excimer pulse-laser ( $\mathrm{XeCl}, 308 \mathrm{~nm}$ ). Initial concentrations of diazinon and metabolite were $40 \mathrm{mg} / \mathrm{L}$.

For irradiation we have chosen three series of each investigated sample. The first series contained only diazinon or its metabolite. Hydrogen peroxide with the concentration of $20 \mathrm{mg} / \mathrm{L}$ has been added to the second series, which contained diazinon or metabolite. The same concentration of hydrogen peroxide $(20 \mathrm{mg} / \mathrm{L})$ and titanium(IV) oxide with the concentration $1 \mathrm{~g} / \mathrm{L}$ have been added to the third series of samples.

Samples of diazinon have been irradiated by laser pulses of 40 or $50 \mathrm{~mJ}$ except for samples containing hydrogen peroxide and titanium(VI) oxide which have been irradiated by laser pulses of $60 \mathrm{~mJ}$.

The samples of metabolite have been irradiated by laser pulses of $50 \mathrm{~mJ}$. After irradiation the samples have been isolated in time intervals ranging from $10 \mathrm{~min}$ to 24 hrs.

All samples have been isolated by liquid extraction of the water phase using chloroform. After the evaporation of the solvent the residues have been dissolved in acetonitrile for HPLC analysis or in hexane for GC analysis.

2.3. GC and HPLC analyses. Agilent 1100 series (HPLC) equiped with DAD detector has been used for the analysis of organophosphorus pesticide and its degradation product. Eclipse XDB-C8 $(25 \mathrm{~cm} \times 4.6 \mathrm{~mm})$ column with mobile phase acetonitril:water 70:30, the flow rate $1 \mathrm{~mL} / \mathrm{min}$ and detection at the wavelenght of $254 \mathrm{~nm}$ has been used. Retention times for diazinon and its metabolite were 4.4 and $1.33 \mathrm{~min}$, respectively.

HP 6890 series (GC) with ECD detector was used for GC analysis. GC conditions were as follows: Supelco SPB-1 $(30 \mathrm{~m} \times 0.53 \mathrm{~mm})$ column and helium as a carrier gas were used; the initial temperature was $80^{\circ} \mathrm{C}$; temperature increased initially by $30^{\circ} / \mathrm{min}$ up to $178^{\circ} \mathrm{C}$, then by $2^{\circ} / \mathrm{min}$ up to $205^{\circ} \mathrm{C}$ and by $30^{\circ} / \mathrm{min}$ up to $300^{\circ} \mathrm{C}$; injector port temperature was $270^{\circ} \mathrm{C}$, detector temperature was $330^{\circ} \mathrm{C}$. One microliter of the sample was injected in the splitless mode. Retention time for diazinon was $15.3 \mathrm{~min}$.

Some samples were investigated also on GC (Varian Star 3400)-MS system (Varian Saturn 4D, GC/MS/MS) to check for the presence of diazoxon. 
Table 1. Comparison among different samples.

\begin{tabular}{lll}
\hline Sample & GC analysis & Ion chromatography \\
\cline { 2 - 3 } & diazinon & sulphate \\
\hline Demineralized water & no signal & no signal \\
Diazinon-pure solution & signal, $40 \mathrm{ppm}$ & no signal \\
Base hydrolysis $(24 \mathrm{~h})$ & no signal & no signal \\
Sulphate standard & - & signal, $30 \mathrm{ppm} *$ \\
Diazinon, seven $50 \mathrm{~mJ}$ energy pulses, isolation $10 \mathrm{~min}$ after irradiation & $20 \mathrm{ppm}$ & signal, $5.5 \mathrm{ppm}$ \\
Diazinon five $50 \mathrm{~mJ}$ energy pulses, isolation $2 \mathrm{~h}$ after irradiation & $12 \mathrm{ppm}$ & signal, $10 \mathrm{ppm}$ \\
Diazinon five $50 \mathrm{~mJ}$ energy pulses, isolation $6 \mathrm{~h}$ after irradiation & $4 \mathrm{ppm}$ & signal, $12 \mathrm{ppm}$ \\
\hline
\end{tabular}

*max. concentration, which can be achieved from 40 ppm of diazinon is $12.6 \mathrm{ppm}$.

2.4. Ion chromatographic determination of sulphate concentration. Sulphate concentrations in the reaction mixtures have been determined by ion chromatography to check the valence state of sulphur after being released from the diazinon molecule. The analyses have been carried out using a Shimatzu LC10Ai liquid chromatograph with a CDD-6A conductivity detector. The Anion $\mathrm{HC}$ column (Alltech) with a mobile phase of $2.1 \mathrm{mM} \mathrm{NaHCO} 3 / 1.6 \mathrm{mM} \mathrm{Na}_{2} \mathrm{CO}_{3}$ has been used; the flow rate was $1 \mathrm{~mL} / \mathrm{min}$. The retention time for sulphate anion was $13.3 \mathrm{~min}$.

\section{RESULTS}

Within the range of concentrations, limited by the solubility of pesticide (up to $40 \mathrm{mg} \mathrm{L}^{-1}$ ), rapid decomposition of the pesticide has been achieved. For $1 \mathrm{~mL}$ samples $120 \mathrm{~mJ}$ of irradiation energy have been needed for $60 \%$ degradation efficiency within one hour following the irradiation, as shown in Figure 1. The isolation of diazinon sample 24 hours after irradiation has however shown total degradation of the pesticide. By increasing the number of irradiation pulses and therefore the total irradiation energy to 250-350 mJ, over 90\% degradation efficiency was achieved.

With the application of catalysts such as $\mathrm{TiO}_{2}$ and $\mathrm{H}_{2} \mathrm{O}_{2}$ comparable efficiencies were obtained by using only $120 \mathrm{~mJ}$ of irradiation energy.

The efficiency of degradation was supported by detection of 2-isopropyl-4-methyl-6-hydroxypyrimidine (IMHP) in all irradiated samples as confirmed by the GC analysis. The IMHP was found to decay further under the specified irradiation conditions. At the same time the corresponding reduction in diazinon concentration was accompanied by the increase of the sulphate concentration in aqeous phase, as shown in Table 1. No evidence for the presence of diazoxon was obtained by GC/MS analysis. This suggests that diazinon is converted directly into IMHP without the formation of diazoxon, which is more toxic compared to its thionoform (diazinon). The sulphur atom is simultaneously oxidised into sulphate ion.

In addition, a series of experiments under the same reaction conditions as those used in studies of diazinon
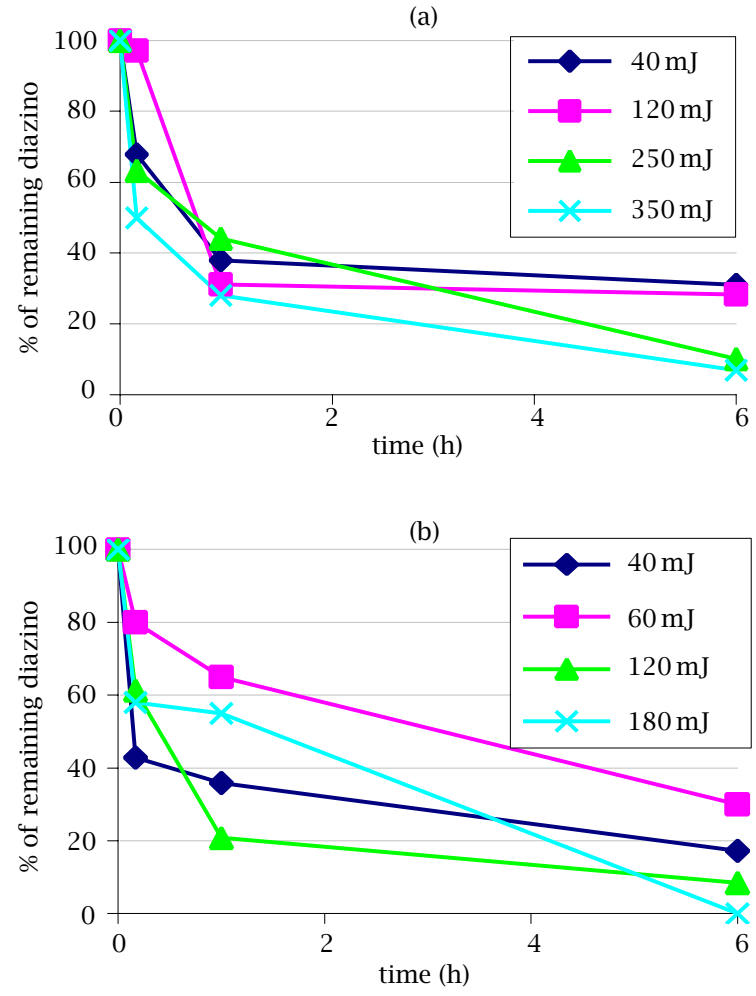

Figure 1. Degradation of diazinon in demineralised water (a) and diazinon in demineralised water in the presence of $\mathrm{H}_{2} \mathrm{O}_{2}$ and $\mathrm{TiO}_{2}$ (b) following irradiation with different laser energies.

were carried out on aqueous solution of the diazinon metabolite to detect its eventual degradation. The results of irradiation experiment have shown that degradation of the metabolite in aqueous solution is minimal.

On the basis of presented results we propose the following mechanism for the photodegradation of diazinon. Oxidation of sulphur takes place as confirmed by ion chromatographic detection of sulphate anion in water phase (Figure 2). Almost simultaneously, oxidation and hydrolysis of the esther bond and release of the metabolite occur. 


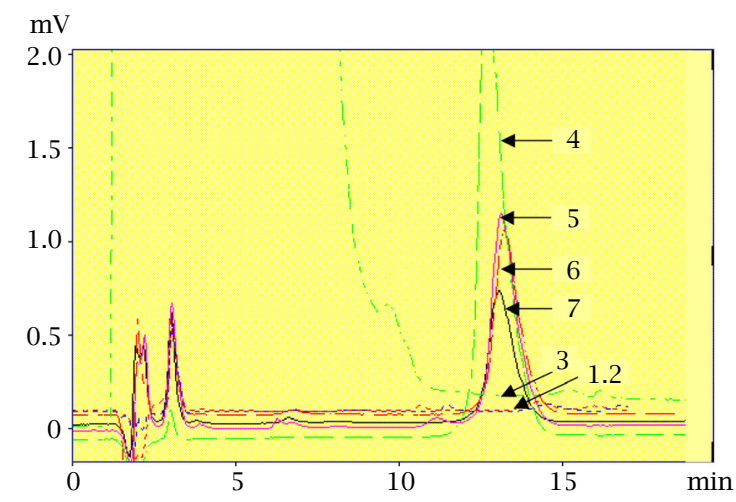

1-Distilled water

2-Diazinon

3-Base hydrolysis of diazinon

4-Sulphate standard, $33 \mathrm{ppm}$

5-Diazinon five $50 \mathrm{~mJ}$ energy pulses, isolation $6 \mathrm{~h}$ after irradiation

6-Diazinon five $50 \mathrm{~mJ}$ energy pulses, isolation $2 \mathrm{~h}$ after irradiation

7-Diazinon seven $50 \mathrm{~mJ}$ energy pulses, isolation $10 \mathrm{~min}$ after irradiation

Figure 2. Determination of sulphate anion in different samples by ion chromatography.

\section{CONCLUSIONS}

It has been demonstrated that by a three fold increase in irradiation energy similar efficiency of diazinon degradation can be achieved as with the addition of $\mathrm{H}_{2} \mathrm{O}_{2}$ and $\mathrm{TiO}_{2}$ when using lower irradiation energy $(120 \mathrm{~mJ})$.

The degradation of diazinon during the irradiation with high energy laser light pulses does not contribute significantly to the overall efficiency of photodegradation. The degradation is however most probably initiated by the presence of hydroxy radicals formed during the irradiation and proceeds at relatively low reaction rates $\left(2 \times 10^{-6} \mathrm{~mol} \mathrm{~min}^{-1}\right)$. Over $70 \%$ of diazinon can be degraded already within the first two hours following the irradiation with the increase in efficiency up to $95 \%$ during the next four hours.

It is worth noting that diazinon is converted directly into 2-isopropyl-4-methyl-6-hydroxypyrimidine without the formation of more toxic diazoxon.

\section{References}

[1] K. D. Racke, Degradation of Organophosphorus Insecticides in Environmental Matrices, in Organophosphates: Chemistry, Fate, and Effects, J. E. Chambers and P. E. Levi (eds.), Academic Press, Inc, 1992, p. 47.
[2] A. Dannenberg and S. O. Pehkonnen, J. Agric. Food Chem. 46 (1998), 325.

[3] V. H. Freed, C. T. Chiou, and D. W. Schmedding, J. Agric. Food Chem. 27 (1979), 3685.

[4] J. A. Noblet, A. A. Smith, and I. H. Suffet, J. Agric. Food Chem. 44 (1996), 3685.

[5] R. S. Givens and L. W. Kueper, Chem. Rev. 93, 1993, 55.

[6] G. Durand, J. L. Abad, F. Sanchez-Baeza, A. Messeguer, and D. Barcelo, J. Agric. Food Chem. 42 (1994), 814.

[7] J. J. Pignatello and Y. Sun, Wat. Res. 29(8) (1995), 1837.

[8] A. Vidal, Z. Dinya, F. MogyorodiJr, and F. Mogyorodi, Applied Catalysis B:Environmental 21(4) (1999), 259.

[9] A. Bianco Prevot, M. Vincenti, A. Bisnciotto, and E. Pramauro, Applied Catalysis B:Environmental 22(2) (1999), 149.

[10] R. Doong and W. Chang, J. Photochem. Photobiol. A: Chem. 177 (1997), 239.

[11] Q. Zhang and S. O. Pehkonen, J. Agric. Food Chem. 47 (1999), 1760.

[12] Y. Ku, J. L. Chang, Y. S. Shen, and S. Y. Lin, Wat. Res. 32 (1998), 1957.

[13] E. L. Puplampu and D. K. Dodoo, J. Photochem. Photobiol. A: Chem. 135(1) (2000), 81.

[14] J. P. Fouassier, Excited-State Properties of Photoinitiators: Lasers and their Applications, in Photopolymerization and Photoimaging Science and Technology, A. S. Norman (ed.), London, New York: Elsevier, 1989.

[15] J. L. Lopez, F. S. Garcia Einsclag, M. C. Gonzalez, A. L. Capparelli, E. Oliveros, T. M. Hashem, and A. M. Braun, J. Photochem. Photobiol. A: Chem. 137 (2000), 177.

[16] C. Gooijer and A. J. G. Mank, Analytica Chimica Acta 400 (1999), 281. 


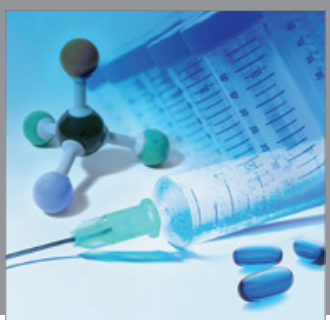

International Journal of

Medicinal Chemistry

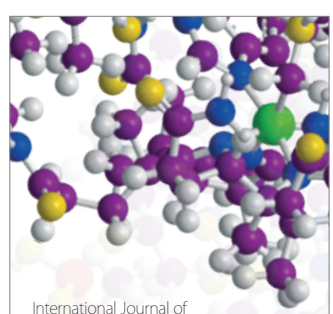

Carbohydrate Chemistry

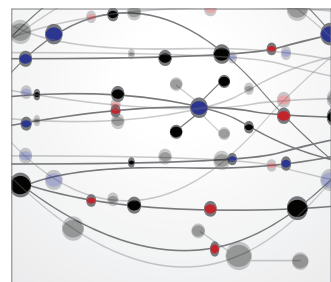

The Scientific World Journal
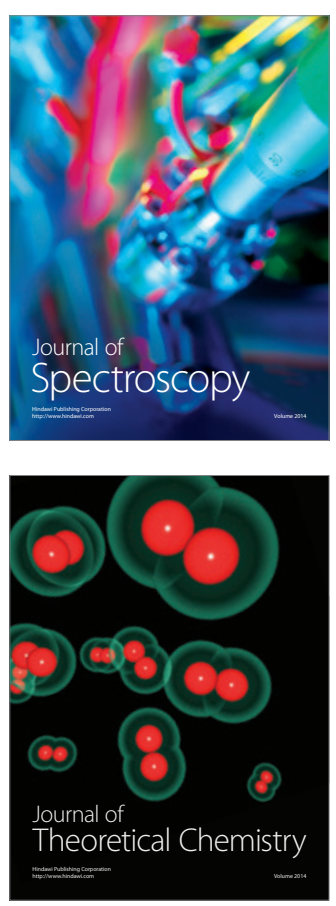
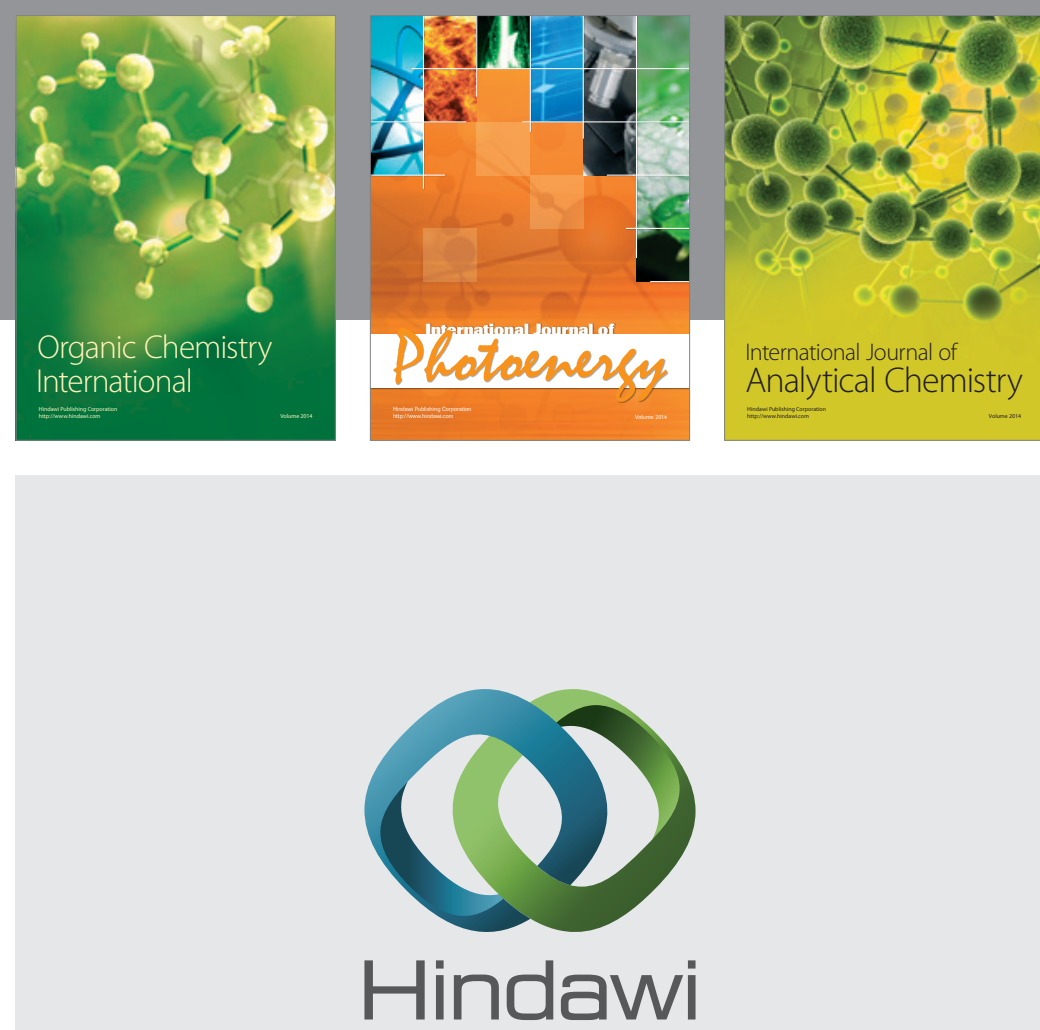

Submit your manuscripts at

http://www.hindawi.com
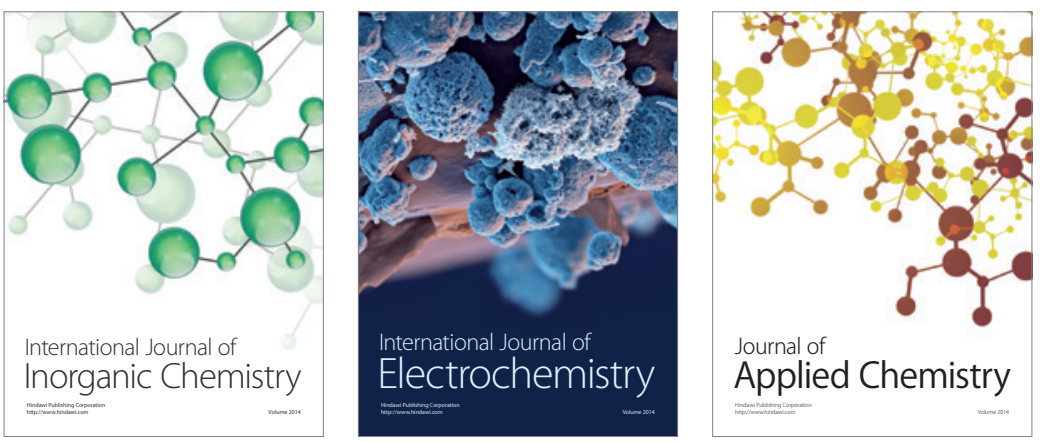

Journal of

Applied Chemistry
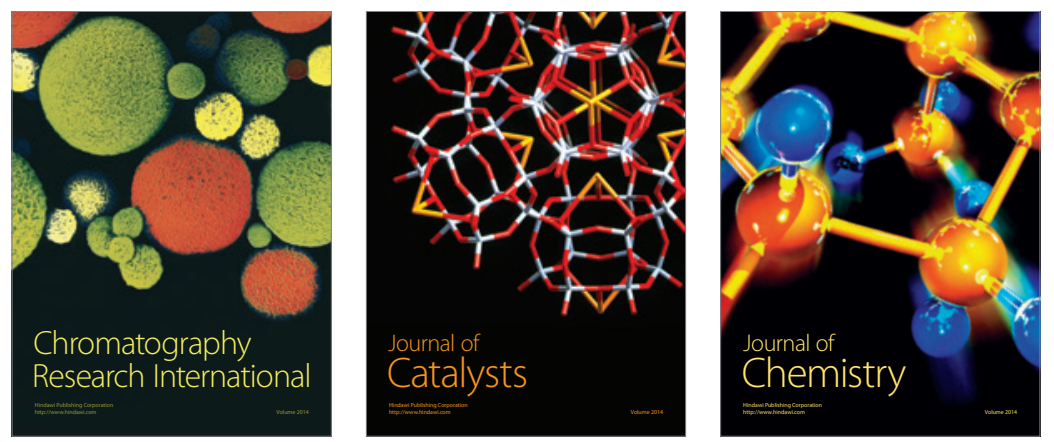
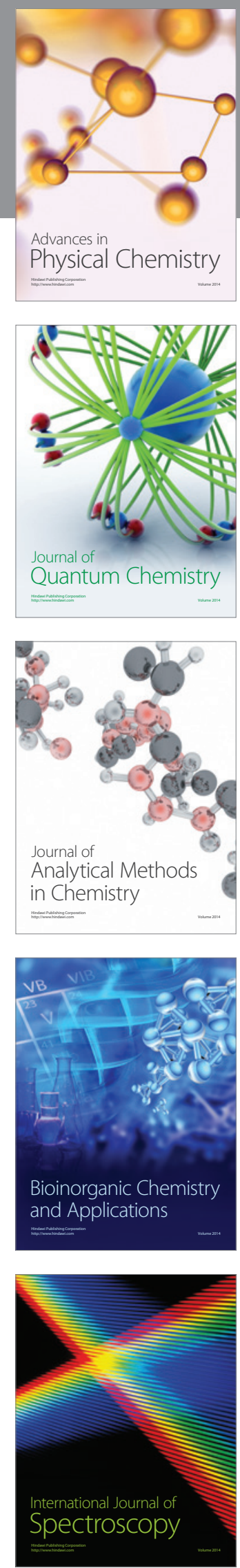